\title{
Toe skin temperature as a guide to epidural anaesthesia dosing
}

Shigehito Sato MD, Yuichiro Akiyoshi MD, Hiromi Ashimura MD, Yukiko Nishijima MD, Naomitsu Okubo MD, Hiroshi Takahashi MD
To determine the time for additional epidural anaesthesia, skin temperature of the big toe was evaluated in 50 patients undergoing mastectomy. Epidural catheters were placed at or near the $T_{5-6}$ intervertebral space and $12 \mathrm{ml}$, lidocaine $1.5 \%$ with 1:200,000 epinephrine were injected. When the skin temperature, which had increased following epidural anaesthesia, decreased by $0.3^{\circ} \mathrm{C}$ without an increase of systolic arterial blood pressure (ABP) of more than 20\%, $8 \mathrm{ml}$ lidocaine $1.5 \%$ were injected. If the skin temperature increased, the monitor was judged to have been useful. When ABP increased $>20 \%$ without a decrease of skin temperature, the monitor was judged not to have been useful. Monitoring of toe skin temperature was useful in 39 patients (78\%) in estimating the time for the first additional dose of epidural anaesthetic. First, second and third intervals between injection were $96.5 \pm 21.0(n=39)$, $69.7 \pm 14.2(n=35)$ and $50.1 \pm 12.2 \min (n=7)$, respectively. We conclude that, when epidural puncture is performed at upper thoracic levels, toe skin temperature can be a useful monitor to judge the time for additional anaesthetic.

Pour déterminer le moment de la dose de rappel pour l'anesthésie épidurale, la température cutanée du gros orteil est mesurée chez 50 patientes pendant une mastectomie. Un cathéter épidural est placé au niveau ou près de $T_{5-6}$. De la lidocaïne 1,5\% avec épinéphrine 1:200000 est injectée. Quand la température déjà en hausse après l'épidurale baisse de $0,3^{\circ} \mathrm{C}$ sans diminution de la tension artérielle (TA) supérieure à $20 \%$, on ajoute $8 \mathrm{ml}$ de lidocaïne 1,5\%. Si la température cutanée augmente, ce type de monitorage est jugé utile. Quand la TA augmente de $20 \%$ sans diminution de la température, le moniteur est jugé inutile. Ce monitorage de la température cutanée est jugé utile chez 39 patients (78\%) pour déterminer le moment

\section{Key words}

ANAESTHETIC TECHNIQUES: epidural; ANAESTHETICS, LOCAL: lidocaine; TEMPERATURE: skin.

From the Department of Anesthesiology, Institute of Clinical Medicine, University of Tsukuba, Ibaraki, 305, Japan.

Address correspondence to: Dr. Shigehito Sato, Department of Anesthesiology, Institute of Clinical Medicine, University of Tsukuba, Tsukuba-shi, Ibaraki-ken, 305, Japan.

Accepted for publication 19th November, 1993. de la première dose de rappel. Le premier, le deuxième et le troisième intervalle entre les injections a été de 96,5 $\pm 21,0$ $(n=39), 69,7 \pm 14,2(n=35)$ et $50,1 \pm 12,2 \min (n=$ 7) respectivement. Nous concluons que lorsque la ponction épidurale est effectuée au niveau thoracique supérieur, la température cutanée du gros orteil peut s'avérer utile pour monitorer le moment d'injection d'une dose anesthésique additionnelle.

It has been suggested that when using continuous epidural anaesthesia, an additional dose of local anaesthetic should be given when the upper segmental level of analgesia has regressed two segments to maintain an effective level of surgical analgesia. ${ }^{1}$ However, in anaesthetized patients, there is no means of estimating the timing of additional doses. Most of the anaesthetists inject additional doses according to their clinical experiences. Frequent injections may cause local anaesthetic toxicity. On the other hand, inadequate redosing may cause increase of blood pressure or heart rate because of pain. Only one report has been described using intermittent electrical stimulation to monitor the regression of epidural analgesia. ${ }^{2}$ However, as this requires that the patient be awake, recession of analgesic level cannot be confirmed during general anaesthesia.

Measuring skin temperature of the finger or toe has been reported as an indirect non-invasive method of evaluating sympathetic activity, ${ }^{3}$ and an increase in foot skin temperature is recognized after spinal and epidural anaesthesia. ${ }^{4-7}$ Previously, we reported that the time of an additional dose of epidural anaesthetic could be estimated in $58 \%$ of patients undergoing upper abdominal surgery by monitoring toe skin temperature. ${ }^{8}$ We suggested that vigorous intra-abdominal manipulation by the surgeon was one reason for failure. In this report, the usefulness of toe skin temperature in assessing the need for epidural redosing was studied in patients undergoing mastectomy.

\section{Methods}

This study included 50 patients undergoing mastectomy (ASA I-II). Patients treated with vasoactive drugs were excluded. The purpose of the study was explained and informed consent was obtained from each patient after 
approval by the institutional human investigation committee. Patients received premedication with diazepam 10 $\mathrm{mg} \mathrm{po,} 90 \mathrm{~min}$ before the start of anaesthesia. Big toe skin temperature was measured continuously with CoreTemp 10 Model CTM-204 (Terumo-Japan Co.) The surface probe of the apparatus, weight $7.0 \mathrm{~g}$, diameter 8.5 $\mathrm{mm}$, was comprised of an electrical heating element and two thermistors separated by an insulator. The probes were attached to the centre of the digital pad of both big toes, and the feet were covered with cotton bandage.

An epidural catheter was placed at or near the $T_{5}$ intervertebral space. Nine ml lidocaine $1.5 \%$ with $1: 200,000$ epinephrine were injected after a test dose of $3 \mathrm{ml}$. Increase of the big toe skin temperature and analgesic levels were confirmed $15 \mathrm{~min}$ after the epidural injection. The big toe, which showed the larger increase of temperature was selected as the monitoring site. Anaesthesia was induced with thiopentone $5 \mathrm{mg} \cdot \mathrm{kg}^{-1}$ and the trachea was intubated after vecuronium $0.2 \mathrm{mg} \cdot \mathrm{kg}^{-1}$. Anaesthesia was maintained with nitrous oxide $(67 \%)$, oxygen and a small dose of isoflurane $(0.2-0.4 \%$ inspired). The concentrations of isoflurane were kept constant throughout the procedure (Datex. Oxicap $(10)$, Finland).

When the big toe skin temperature decreased by $0.3^{\circ} \mathrm{C}$ over five minutes, $8 \mathrm{ml}$ lidocaine were injected. If the skin temperature increased, the monitor was judged to have been useful. If systolic arterial blood pressure (ABP) increased by $>20 \%$ without a decrease in skin temperature or if its skin temperature decreased and then failed to increase following redosing, the monitor was considered not to have been useful. As a preparatory experiment, we studied the efficacy of toe skin temperature monitoring for epidural anaesthesia in awake patients undergoing lower abdominal surgery. The toe temperature was not useful because we had to redose according to the patient's complaint of pain and an elevation of ABP before the decrease of temperature. Therefore in the present study, we hypothesized that elevation of ABP which occurred before temperature decrease was due to inadequate surgical anaesthesia.

The effect of general anaesthesia alone on toe skin temperature was evaluated in ten patients.

Ambient temperature in operating rooms were maintained at between 23 and $25^{\circ} \mathrm{C}$.

Data are presented as mean $\pm \mathrm{SD}$ and comparisons of each skin temperature and interval time were performed by ANOVA. A $P$ value of $<0.05$ was considered to be significant.

\section{Results}

Patients were all female and their age, height, and body weight were $49.5 \pm 10.4 \mathrm{yr}, 153.2 \pm 5.3 \mathrm{~cm}$, and 51.7 $\pm 4.9 \mathrm{~kg}$, respectively. Skin temperature changes in the
TABLE I Skin temperatures in the big toe (mean $\pm \mathrm{SD},{ }^{\circ} \mathrm{C}$ )

\begin{tabular}{llll}
\hline & Baseline & 15 min after EA & 10 min after $G A$ \\
\hline EA $(+)$ & $29.4 \pm 2.9$ & $32.4 \pm 3.8^{*}$ & $35.9 \pm 1.0^{*} \dagger$ \\
EA $(-)$ & $30.0 \pm 2.5$ & - & $34.9 \pm 1.5^{*}$ \\
\hline
\end{tabular}

$* P<0.0 \mathrm{I}$ vs baseline. $\dagger P<0.05$ vs EA $(-)$.

EA: epidural anaesthesia, GA: general anaesthesia.

TABLE II Incidence of effective cases and interval time of additional doses

\begin{tabular}{llll}
\hline & First & Second & Third \\
\hline $\begin{array}{l}\text { Effective cases } \\
\quad 39 / 50\end{array}$ & $35 / 38$ & $7 / 9$ \\
$\begin{array}{c}\text { Interval Time } \\
\text { (min) }\end{array}$ & $(78)$ & $(77.8)$ & $(92.1)$ \\
\hline
\end{tabular}

$* P<0.01$ vs first interval time.

big toes with or without epidural anaesthesia are shown in Table $\mathbf{I}$.

Fifteen minutes after the epidural injection, the upper anaesthetic level for pin prick was $T_{1} \pm 3.2$ and the lower level was $T_{9} \pm 2.5$. Ten minutes after the induction of general anaesthesia, the toe skin temperature reached a stable level, $35.9 \pm 1.0^{\circ} \mathrm{C}$. In the control group of ten patients without epidural anaesthesia, the toe skin temperature increased $34.9 \pm 1.5^{\circ} \mathrm{C}$ within ten minutes after general anaesthesia. The toe skin temperatures with epidural anaesthesia were higher than during general anaesthesia alone $(P<0.05)$. Ephedrine $5 \mathrm{mg} i v$ was used in five patients after the induction of general anaesthesia, no other intravenous drugs, such as analgesics and/or vasodilators were used.

In 39 patients (78\%), the monitor was useful in judging the time for its first additional dose (Table II). In 11 patients, an additional dose was injected because ABP increased by $>20 \%$. In these failed cases, the toe temperature did not decrease before elevation of ABP. The number of patients in whom the temperature monitor was judged to be useful decreased to 35 , and 7 for the second and third injections. A typical case is shown in Figure 1.

\section{Discussion}

It has been reported that sensory and motor nerve functions return before sympathetic nerve activity. ${ }^{4,9}$ Therefore when using epidural anaesthesia, monitoring of sympathetic nerve activity is not considered to be useful in determining the time for additional dosing. In the present study, we judged the time of an additional dose in $78 \%$ of patients undergoing mastectomy by using the change of toe skin temperature. 


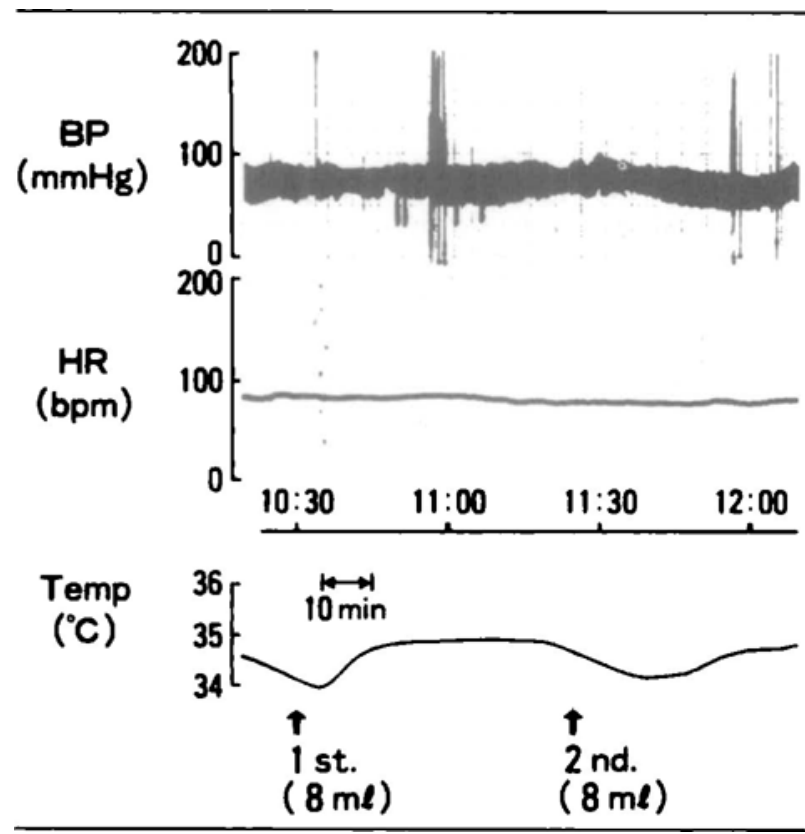

FIGURE 1 One example of course of blood pressure (BP), heart rate (HR) and toe skin temperature. When temperature decreased from $34.8^{\circ} \mathrm{C}$ to $34.5^{\circ} \mathrm{C}$, first additional dose (1st) was injected. Second additional dose (2nd) was also injected according to the decrease of toe skin temperature without any significant change of BP and HR.

Vasoactivity of the lower extremities is controlled by sympathetic outflow from $T_{11}$ to $L_{2}$ spinal cord. ${ }^{10}$ As the caudal border of the analgesia level at $15 \mathrm{~min}$ after epidural injection was $T_{9} \pm 2.5$, sympathetic nerve block might have exceded this boundary. As the anaesthetic effect, during regression, begins to disappear in places distal from the injected site, we assume that toe skin temperature decreased before the decay of surgical analgesia (Figure 2). Induction of general anaesthesia $15 \mathrm{~min}$ after epidural injection produced more increase in toe skin temperature (Table I). However, in the present study, toe temperature ten minutes after induction of general anaesthesia was higher with epidural anaesthesia than without epidural anaesthesia. We think that this is one of the reasons why we can observe the decrease of toe temperature by the recession of epidural anaesthesia during general anaesthesia. In a previous study, the hand (thumb) skin temperature was not found to be useful. ${ }^{8}$ In mastectomy, the thumb temperature cannot be used as a monitor for this study, since the regional analgesia must extend at least from $T_{1}$ to $T_{10}$.

We injected $12 \mathrm{ml}$ (including $3 \mathrm{ml}$ test dose) lidocaine $1.5 \%$ with 1:200,000 epinephrine as an initial dose. We used lidocaine with epinephrine to preclude intravascular injection but perhaps plain lidocaine would have been preferred to confirm multiple injections. Fifteen minutes after the injection, toe skin temperature increased from

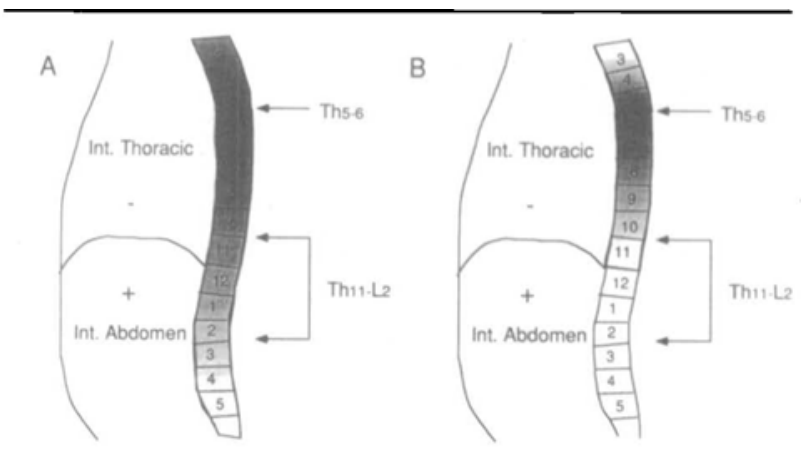

Just after the injection

Regression of the effect in Th11-L2

FIGURE 2 Schema for the possible explanation of our hypothesis of successful monitoring of toe skin temperature. (A) Just after the initial injection of local anaesthetic. As the sympathetic nerves derived from $\mathrm{T}_{11}-\mathrm{L}_{2}$ are anaesthetized, toe skin temperature increases. (B) Phase of regression of the anaesthetic effect. When the anaesthetic effect of $T_{11}-L_{2}$ decays, toe skin temperature starts to decrease. Shade of figure shows the degree of lidocaine concentration remaining in nerve fibres at the effective site of epidural anaesthesia.

$29.4 \pm 2.9^{\circ} \mathrm{C}$ to $32.4 \pm 3.8^{\circ} \mathrm{C}$. Hopf et al..$^{5}$ indicated that toe temperature increased approximately $20 \mathrm{~min}$ after the establishment of thoracic sensory analgesia. Although we could have waited for a longer time to confirm maximum elevation of temperature, we judged the sympathetic nerves to lower extremity were anaesthetized with the initial $12 \mathrm{ml}$ lidocaine. For redosing, we injected a volume of $8 \mathrm{ml}$ lidocaine in all cases. As we observed an increase of toe temperature in 39 patients after the first redosing, we believe that this dose was sufficient to provide adequate anaesthesia.

Hopf $e t$ al. ${ }^{5}$ described that toe temperature increased even after high thoracic epidural anaesthesia. He did not describe whether the decrease in toe temperature was correlated with regression of thoracic analgesia. One would expect that there would be a delay in the decrease in sensory analgesia with thoracic epidural analgesia. However, we found earlier decrease of toe temperature than elevation of $A B P$, probably in response to surgical pain.

Several causes of failure might be considered, including unequal spread of local anaesthesia, insufficient depth of general anaesthesia, intratracheal intubation and improper protection of the foot from ambient temperature.

In conclusion, when epidural puncture was performed near the $T_{5}$ level, the big toe temperature was a useful monitor to judge the time for redosing in patients undergoing mastectomy.

\section{References}

1 Bromage PR. Epidural Analgesia. Philadelphia: WB Saunders Co, 1978; 215-57. 
2 Andrade PA, Wikinski JA. Monitor of sensory level during epidural or spinal anesthesia. Anesthesiology 1980; 52: 189-90.

3 Bengtsson $M$, Nilsson GE, Löfström JB. The effects of spinal analgesia on skin blood flow, evaluated laser Doppler flowmetry. Acta Anaesthesiol Scand 1983; 27: 206-10.

4 Daos FG, Virtue RW. Sympathetic-block persistence after spinal or epidural analgesia. JAMA 1963; 183: 285-7.

5 Hopf $H B$, Weissbach B, Peters $J$. High thoracic segmental epidural anesthesia diminishes sympathetic outflow to the legs, despite restriction of sensory blockade to the upper thorax. Anesthesiology 1990; 73: 882-9.

6 Bengtsson $M$. Changes in skin blood flow and temperature during spinal analgesia evaluated by laser doppler flowmetry and infrared thermography. Acta Anesthesiol Scand 1984; 28: 625-30.

7 Peters J, Kousoulis L, Arndt JO. Effects of segmental thoracic extradural analgesia on sympathetic block in conscious dogs. Br J Anaesth 1989; 63: 470-6.

8 Sato S, Yamaguchi $H$, Okubo N, Fukuda T, Naito $H$. Change in skin temperature as a guide to timing supplementary doses during epidural anesthesia. Japanese Anaesthesia Journals' Review 1989; 3: 127-30.

9 Roe CF, Cohn FL. Sympathetic blockade during spinal anesthesia. Surg Gynecol Obstet 1973; 136: 265-8.

10 Murphy TM. Spinal, epidural, and caudal anesthesia. In: Miller RD (Ed.). Anesthesia, Vol. 2, 2nd ed. New York: Churchill Livingston, 1986; 1061-111. 